\title{
Android Educational Game: Introduction to Basic Logic for Children
}

\author{
Nurul Ria Irawan \\ State Agricultural Polytechnic \\ Samarinda \\ Software Engineering Technology, \\ Agricultural Management \\ Samarinda, Indonesia \\ nrriairawan2330@gmail.com
}

\author{
Nisa Rizqiya Fadhliana \\ State Agricultural Polytechnic \\ Samarinda \\ Software Engineering Technology, \\ Agricultural Management \\ Samarinda, Indonesia \\ nisafadhliana@gmail.com
}

\author{
Wahyu Eka Sari \\ State Agricultural Polytechnic \\ Samarinda \\ Software Engineering Technology, \\ Agricultural Management \\ Samarinda, Indonesia \\ wahyunisari52@gmail.com
}

\begin{abstract}
Introduction to Basic Logic aims to develop children's thinking abilities about numbers and quantities to teach activities that are in accordance with the development of Reviews their thinking power. Learning in children requires an educational game media facility, one of the which is the Educational Game. This educational-type game aims to Provoke children's interest in learning the subject matter while playing the game. Mobile games can be an alternative in children's learning. Basically children prefer to play rather than learn. This is natural, Because child psychology is playing.
\end{abstract}

Reviews These problems based on an educational game application is made for the introduction of basic logic in the Android-based children, so that it can produce alternative learning for children. This educational game is intended for children aged 6-7 years Because of children aged 6-7 years have begun to understand the concept of numbers and develop sensitivity in solving a problem. And trials are Carried out using a questionnaire.

Keywords- Educational Game, android, basic logic recognition, kids.

\section{INTRODUCTION}

Education is a universal activity in human life. Education is now very big influence on a person's basic abilities and characteristics. The learning process in children should be performed aimed to provide basic concepts about education that are important in the lives of Mathematics (Logic). Learning about the logic of children is playing an important role in the curriculum of the children to develop the ability to think about the number and quantity of teaching activities in accordance with the development of their thinking power. The learning process in children should be done with the aim of providing the basic concepts that have significance for the child through a real experience that allows children to show activity and curiosity optimally. Computers now become a medium of learning for children. Learning through computers that apply to the children of course can stimulate their intelligence, such as cognitive intelligence about understanding the concept of numbers and intelligence Language and hone the ability to think critically. Computers now become a medium of learning for children. One example of technological developments favored and developed by children is Game. It can be seen from the many learning programs in a game. Through a game expected that children can undergo teaching and learning activities in a relaxed and pleasant. eg cognitive intelligence about understanding the concept of numbers and intelligence Language and hone the ability to think critically. Computers now become a medium of learning for children. One example of technological developments favored and developed by children is Game. It can be seen from the many learning programs in a game. Through a game expected that children can undergo teaching and learning activities in a relaxed and pleasant. eg cognitive intelligence about understanding the concept of numbers and intelligence Language and hone the ability to think critically. Computers now become a medium of learning for children. One example of technological developments favored and developed by children is Game. It can be seen from the many learning programs in a game. Through a game expected that children can undergo teaching and learning activities in a relaxed and pleasant.

Based on the above background, it can be formulated problem is how to make the Basic Logic Educational Game App by using software constuct 2 .

Based on the formula above problems, the authors make a boundary problem in making these applications include:

1. The application generates a $2 \mathrm{D}$ game using an application form Construct 2 and HTML 5 programming language.

2. This application diperuntunkan for elementary school children aged 6-7 years.

3. Application has 3 different levels and stages, namely, easy, medium, and hard.

The research aimed to be achieved is to Create and develop educational game software $2 \mathrm{D}$ on the implementation constuct 2 for children in learning. And determine the feasibility of the introduction of the logic of educational games for children aged 6-7 years. The expected result is the kids can practice the use of logic, analyze, and solve problems. And children can take advantage of emerging technologies today as a learning medium.

\section{RESEARCH METHODS}

\section{A. Place and time}

This research was conducted at the place 3 Elementary School wilaya Samarinda Seberang. The research was conducted on the first semester of 2018-2019 doctrine implemented over a period of less than 6 (six) months starting from the month of October 2018 - March 2019 consisting of the preparation of the information collection of data and compilation of the report. 


\section{B. Tools and Materials}

Tools used:

1. Laptop (Ram 4GB DDR3 Memory, 500GB HDD, 14.0 HD LED LCD)

2. printer

3. Applications Cunstruct 2

4. Adobe Photoshop CC 2017

5. Mouse

6. Internet access

7. Stationary

Materials used:

1. Visual object in the form of PNG and GIF.

2. Material short on knowledge Game Logic child.

\section{Work procedures}

Step-by-step method for making the application of this research can be seen as shown below:

1. Needs analysis

An initial step of this study is to determine the form of software and hardware equipment that will be used in the application process research.

The second step is to ask directly in oral form to the parents till 4-5 grade 1 and 2 that the majority of students enjoy the game, they spent more time to play games both at school and at home.

2. Manufacture Plot Scenario

Scenario games used to determine the flow of the game will be made. Where is the player who will be playing this game is the students grade 1 and 2 . There are three different stages, namely stage easily, g medium and difficult stage.

3. Interface design application user interface is one of the important things that can help users interact with the application. Users will get the desired information easily according to the given user interaction input into the application.

4. Making the Program Code

After the design stage or storyboard interface design is then performed conversion into the application design codes specific programming language desired.

5. Game testing

Running an application that has been created. If there is no error, then it will go to the next stage. If there are errors, the application will go to the previous facing.

6. Implementation.

Test application to elementary school children. results or the manufacture, testing, as shown in the diagram below.

And the result or the manufacture, testing, as shown in the figure below.

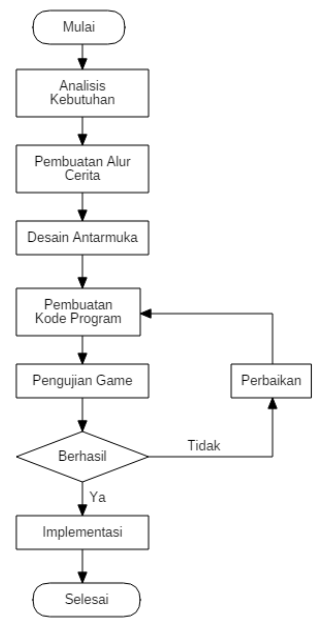

Picture 1 flowchart Research

D. storyboard

1) Main Menu Display

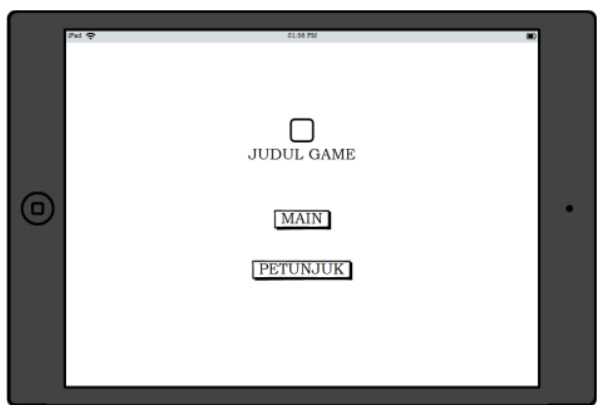

Picture 2 Main Menu Display

In this game there is to see two menu titles and content, namely:

a) Main, on this item the user will start the game.

b) hint

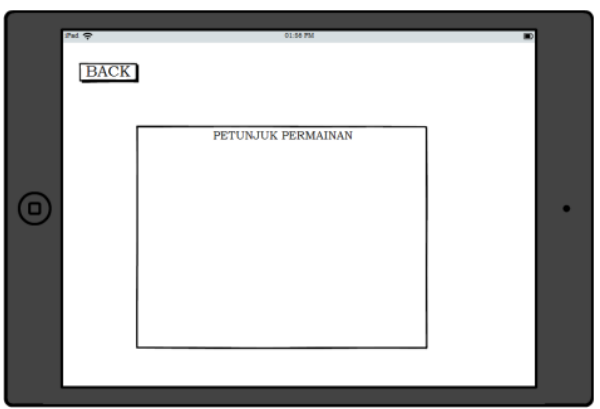

Picture 3 display instructions

Before a user to play this game are advised to see and read the instructions menu content in order to understand explanation of the game, how to play the game and gameplay keyboard functions. 
2) Stage display

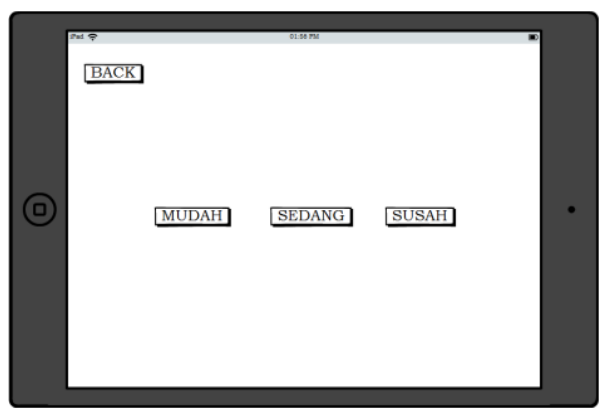

Picture 4 Stage display

On viewing the main menu there are three menu stages, namely:

a) Stage Display Easy

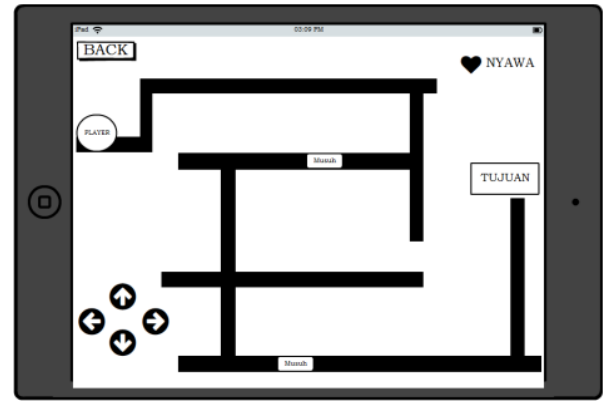

Picture 5 Stage Display Easy

On Stage easy game players are faced with an easy stage. On display are the back button to return to the main menu. And there is a gameplay keyboard to move the object of the game up, down, right side to the left to get to the destination. There are 3 nyawan and 2 enemy player must dodge enemies and if players hit 3 times in the game the player will lose. Players must complete the 3 levels in the easy stage to enter the stage of being.

b) Stage Display Medium

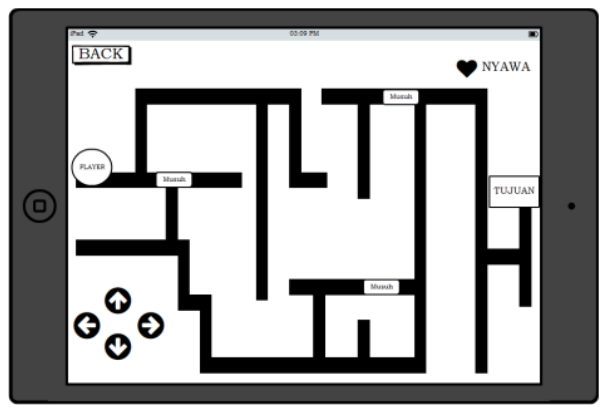

Picture 6 Stage Display Medium

On stage were easy game players are faced with an easy stage. On display are the back button to return to the main menu. And there is a gameplay keyboard to move the object of the game up, down, right side to the left to get to the destination. There are 3 nyawan and 3 enemy players must dodge enemies and if players hit 3 times in the game the player will lose. Players must complete the 3 levels in the moderate stage to get into the difficult stage

c) Difficult Stage Display

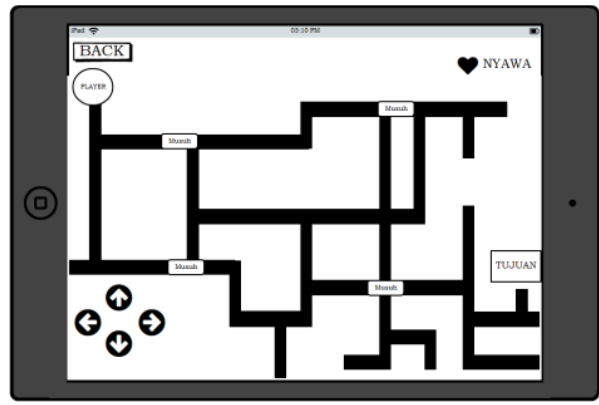

Picture 7 Difficult Stage Display

On easy difficulty Stage game players are faced with an easy stage. On display are the back button to return to the main menu. And there is a gameplay keyboard to move the object of the game up, down, right side to the left to get to the destination. There are 3 nyawan and 4 enemy players must dodge enemies and if players hit 3 times in the game the player will lose. If the player has completed all levels of the existing stage in the game then the game will be completed.

3) views Quiz

There are two layouts on display quiz are:

a) Added views

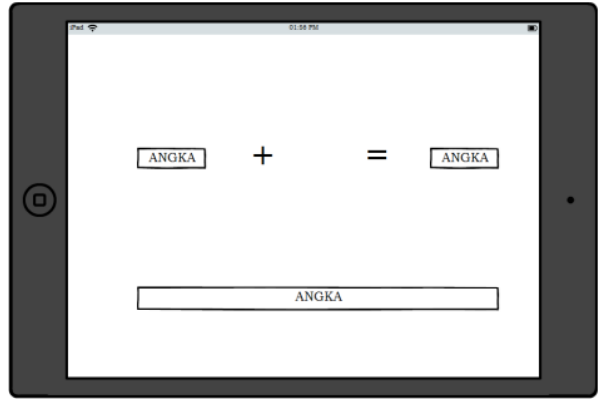

Picture 8 Added views

On the layout there are the numbers 0 through 9 , and there is a quiz which players have to answer correctly. In the quiz there are numbers that are empty, the only player to press and hold the numbers correct answer to a number of questions the quiz empty if true then the number will be enlarged and the game will proceed to the next level, if you lose the numbers going back to the early posis on the layout.

b) views Reduction

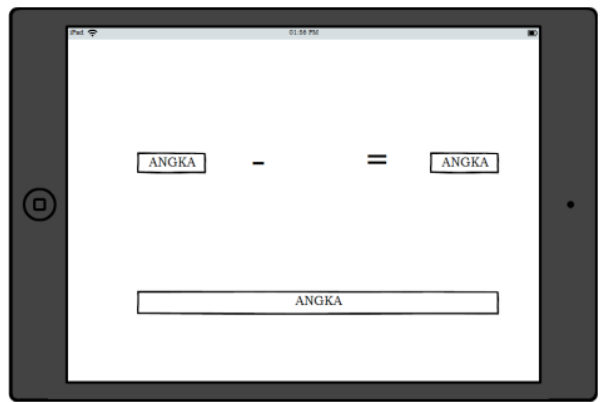

Picture 9 views Reduction

On the layout there are the numbers 0 through 9 , and there is a quiz which players have to answer correctly. In the quiz there are numbers that are empty, the only 
player to press and hold the numbers correct answer to a number of questions the quiz empty if true then the number will be enlarged and the game will proceed to the next level, if you lose the numbers going back to the early posis on the layout.

4) Pop-Up Lost

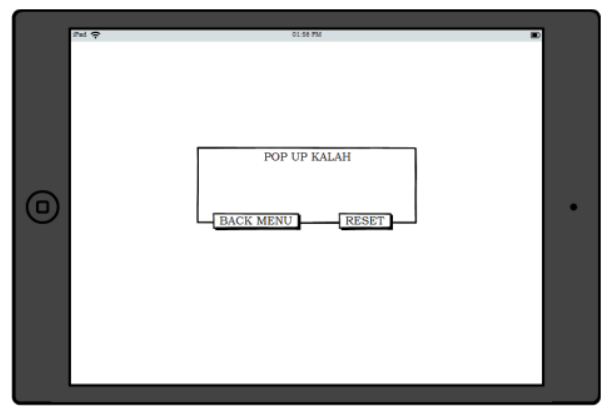

Picture 10 Pop-Up Lost

pop $U p$ the loser will appear if the player runs out of lives lost and 3 times in the game.

5) Pop-Up Win

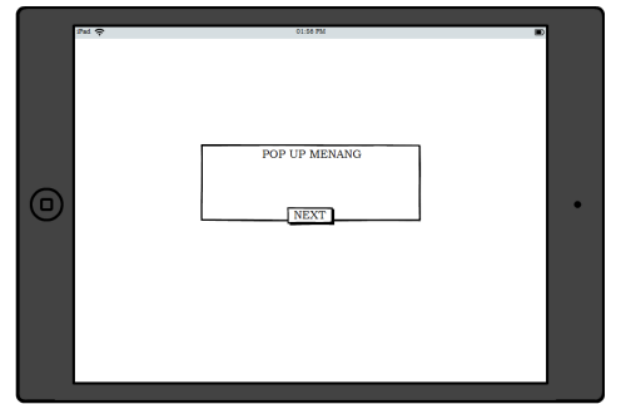

Picture 11 Pop-Up Win

pop $U p$ win would appear if the player manages to answer the quiz increase or reduction to the correct answer.

\section{E. Draft User Interface}

There are some interface design is the Main Menu, Help, Stage, Layout Game and Quis Added

\section{1) Main course}

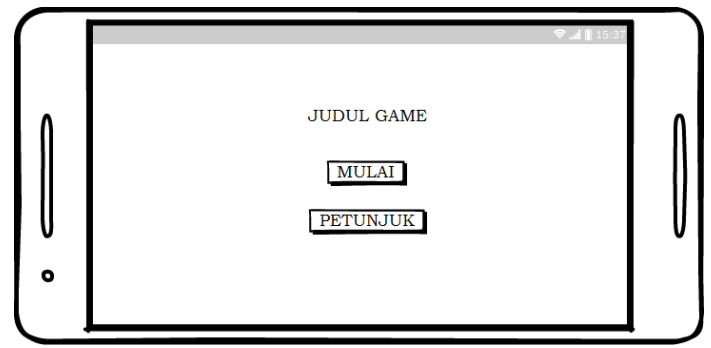

Picture 12 Main Menu Interface Prototype

Main Menu layouts are Title Game and 2 button is the Start and Help. The Start menu is intended for players who want to start an adventure game. User menu allows the player to get an explanation of the game, how to play and function.

\section{2) hint}

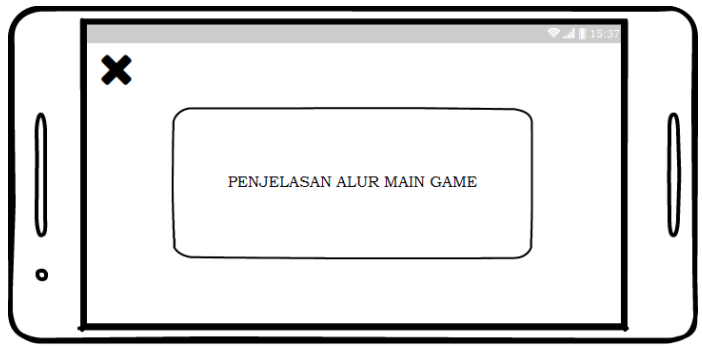

Picture 13 Prototype Interface Guidelines

Layout instructions on players getting information and explanations on how to play the game. And there is a back button.

3) stage

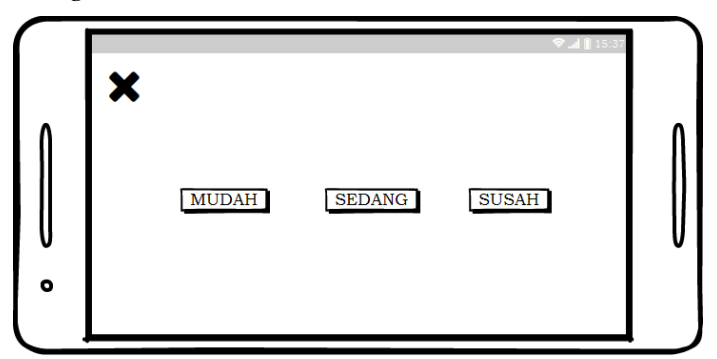

Picture 14 Interface Prototype Stage

Stage Layout there are 3 buttons are easy, medium, and hard. On stage is the players will be faced with gameplay that is easy. On stage was the player will be faced with the groove being. While in the difficult stage players will be faced with a difficult gameplay.

4) layout Level

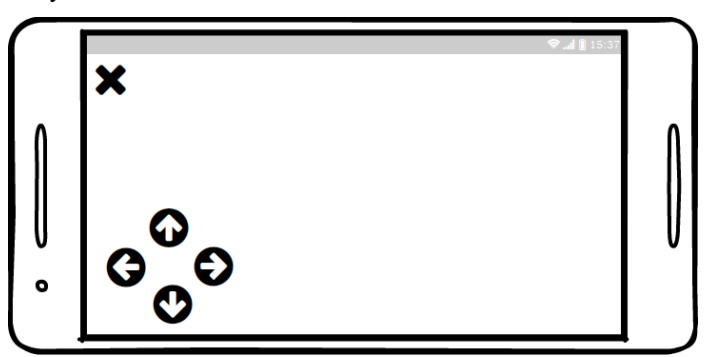

Picture 15 Prototype Interface Layout Level

On There is a level layout keyboard player games to move towards the top, bottom, right, and left and there is a back button if you want to get out of the layout level.

5) Quiz Added

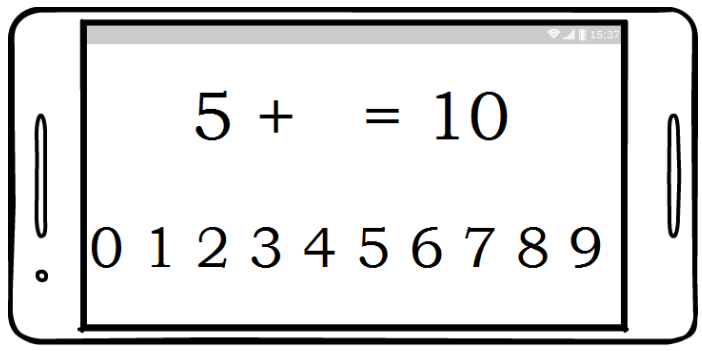

Picture 16 Quiz Interface Prototype Added

Layout Quiz accretion are questions that must be completed by filling in the blanks with the numbers correct numbers. And there is a selection of numbers from 0 to 9 . 


\section{6) Reduction Quiz}

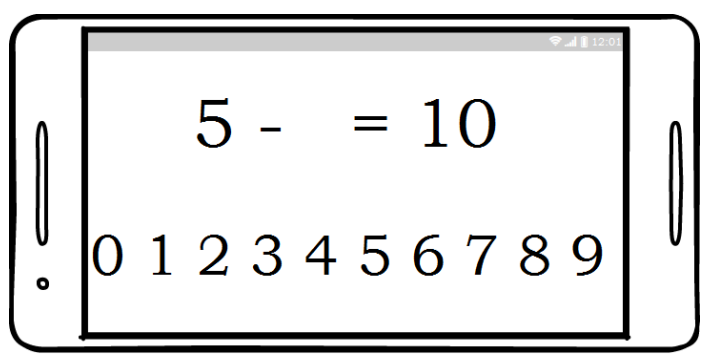

Picture 17 Interface Prototype Reduction Quiz

Under Layout reduction Quiz are questions that must be completed by filling in the blanks with the numbers correct numbers. And there is a selection of numbers from 0 to 9 .

\section{RESUlTS AND TESTING}

\section{A. result}

Following This is the results and discussion of applications Educational Games for Kids Introduction Basic Logic based on Android. This display is made in a manner to support everything that is required by the software to run properly.

\section{1) Main Menu page}

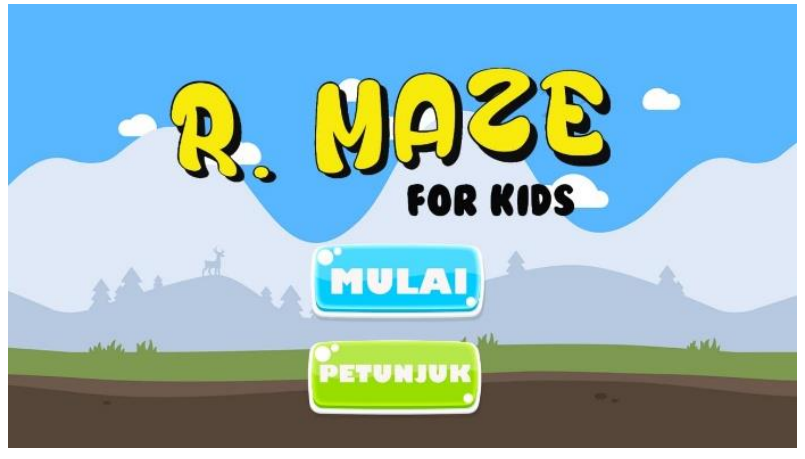

Picture 18 Main Menu page

The main menu is a page containing the title game, the Start menu and Help. The Start menu is used to start the game. And there is a hint menu.

\section{2) Weather Tips}

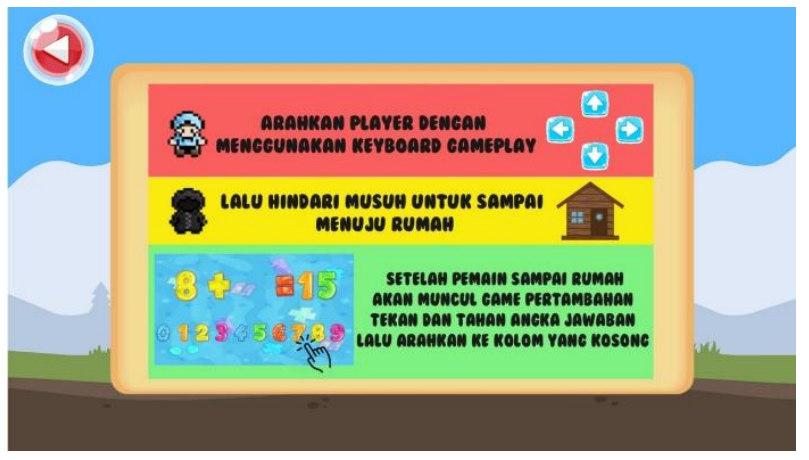

Picture 19 Weather Tips

Manual page contains a brief explanation of the game and play the game. Functioning back button to return to the main menu page.

\section{3) Weather Story Game}

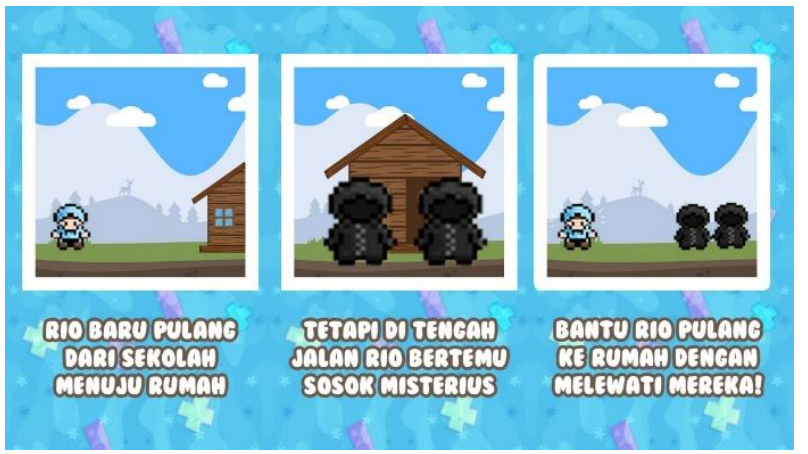

Picture 20 Weather Story Game

On Story pages games, a page that displays the story of the player to the mission that will be played by the player.

\section{4) Stage pages Level}

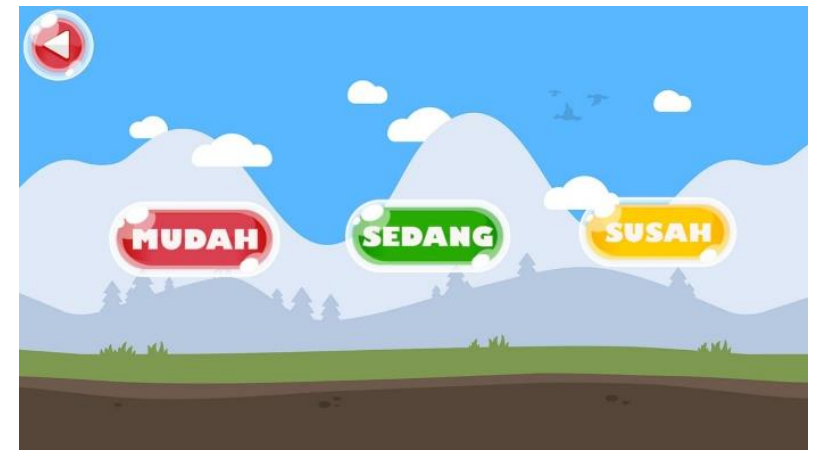

Picture 21 Stage pages Level

Maps stage level, is a page that serves to provide Operagame levels. There are three stages in the first stage, there are 3 levels. The Back button is used to return to the main menu page.

5) Stage pages Easy

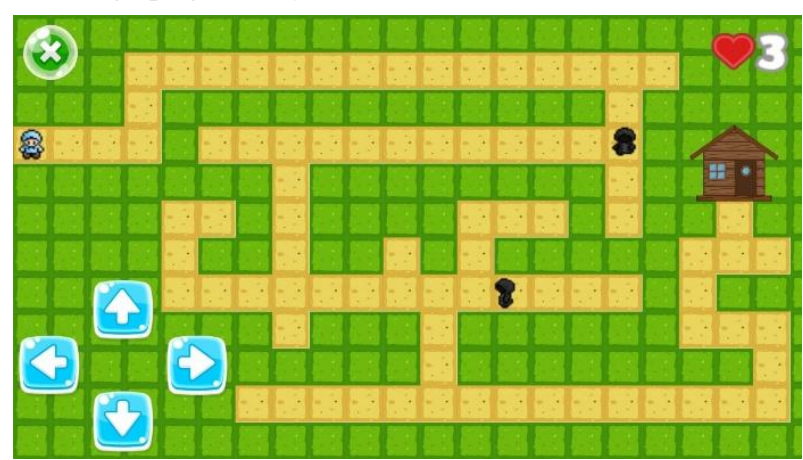

Picture 22 Stage pages Easy

At the stage of page views is easy. Players must complete the challenge by directing the player to use a keyboard game for the past two enemies to get to the house. Players must complete a level 1 first so that it can enter into the next level, as well as beyond. The Back button is used to exit the game level stage.

\section{6) Stage pages Medium}




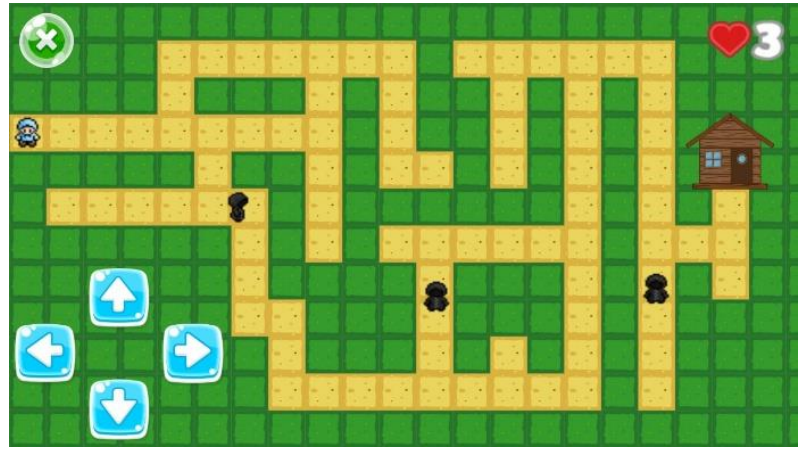

Picture 23 Stage pages Medium

At the stage of page views being. Players must complete the challenge by directing the player to use a keyboard game for the past 3 enemy to get to the house. Players must complete a level 1 first so that it can enter into the next level, as well as beyond. The Back button is used to exit the game level stage.

\section{7) Difficult Stage page}

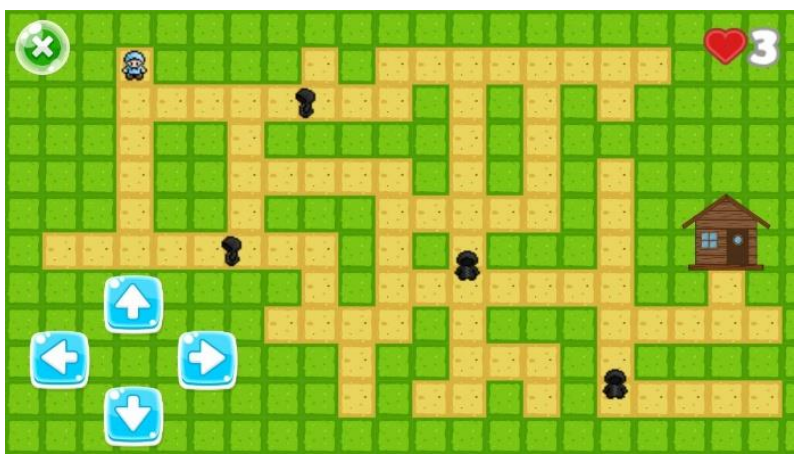

Picture 24 Difficult Stage page

In the difficult stage of page views. Players must complete the challenge by directing the player to use a keyboard game for the past four enemies to get to the house. Players must complete a level 1 first so that it can enter into the next level, as well as beyond. The Back button is used to exit the game level stage.

\section{8) Maps Player Lose}

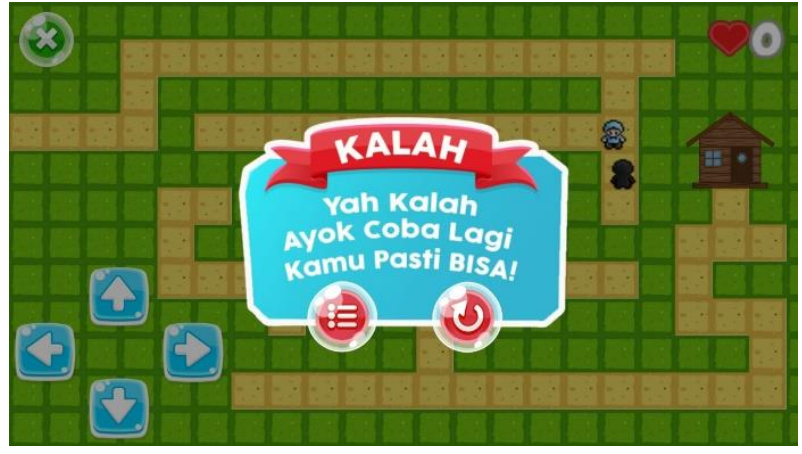

Picture 25 Maps Player Lose

Shown when lives are affected by an enemy player 0 as much as 3 kalli. Right button to repeat the game and the button to the left to go back to the stage.

\section{9) Added Quiz page}

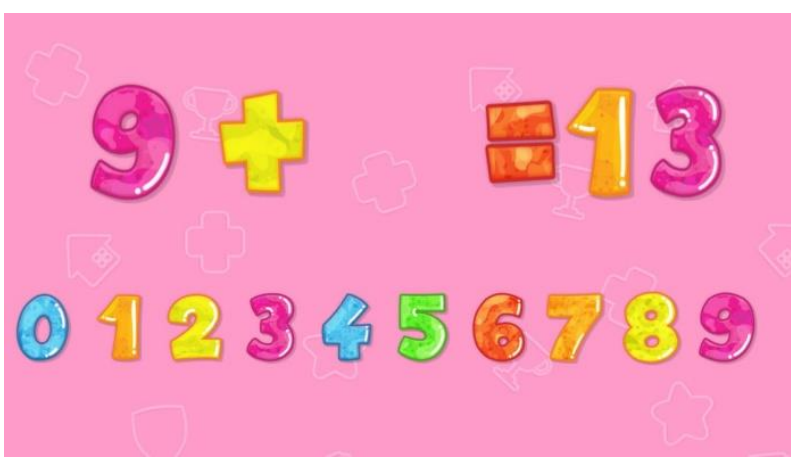

Picture 26 Added Quiz page

Added Quiz page consists of 10 digits are 0 through 9. To answer the question accretion on the layout.

\section{0) Reduction Quiz page}

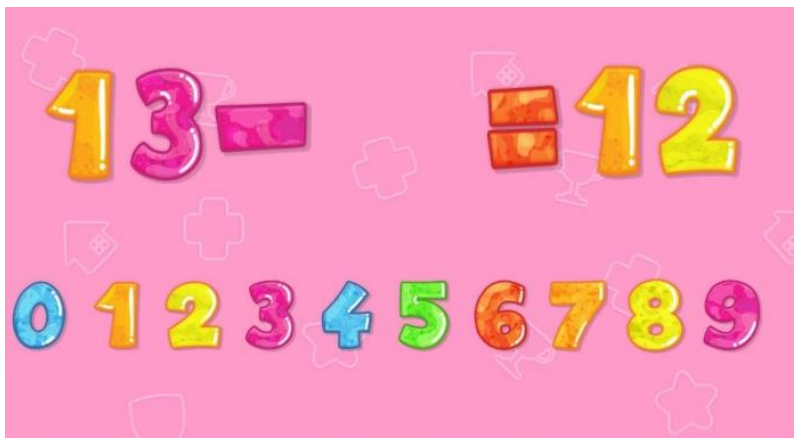

Picture 27 Reduction Quiz page

Added Quiz page consists of 10 digits are 0 through 9. To answer the question accretion on the layout.

11) Maps Win

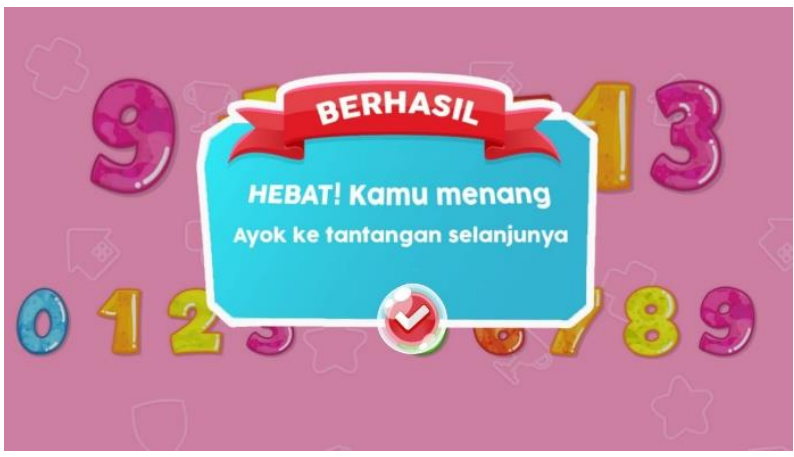

Picture 28 Maps Win

Winning page will appear when the player answered the question correctly. And the center button to continue the game to the next level.

\section{2) Finis page}




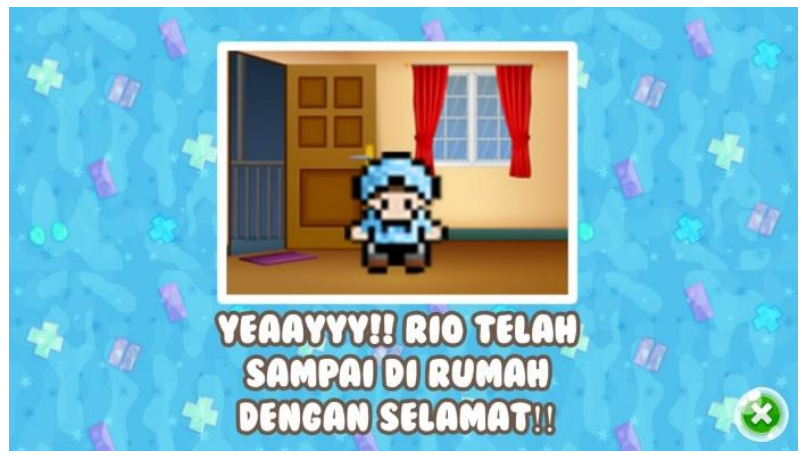

Picture 29 Finish page

Finish the game page, a page that displays that players have been able to finish the game.

\section{B. Discussion}

\section{1) testing Applications}

Here are the results of tests performed by the authors:

TABEL I TEST APPLICATION

\begin{tabular}{|c|c|c|}
\hline Component & Expected results & result \\
\hline $\begin{array}{l}\text { Button Main } \\
\text { Menu }\end{array}$ & $\begin{array}{l}\text { If the button is clicked will go into } \\
\text { the page layout stage }\end{array}$ & succeed \\
\hline Button Hints & $\begin{array}{l}\text { If the button is clicked will go to a } \\
\text { page layout instructions }\end{array}$ & succeed \\
\hline Easy Button & $\begin{array}{l}\text { If the button is clicked will go to } \\
\text { stage the game is level } 1\end{array}$ & succeed \\
\hline Button Medium & $\begin{array}{l}\text { If the button is clicked will go to } \\
\text { stage the game was level } 1\end{array}$ & succeed \\
\hline Button Difficult & $\begin{array}{l}\text { If the button is clicked will go into } \\
\text { the game difficulty level stage } 1\end{array}$ & succeed \\
\hline $\begin{array}{l}\text { Button Back on } \\
\text { Stage Layout and } \\
\text { Layout Guidelines }\end{array}$ & $\begin{array}{l}\text { If the button is clicked it will go to } \\
\text { the Main Menu display }\end{array}$ & succeed \\
\hline $\begin{array}{l}\text { Button Keyboard } \\
\text { Game }\end{array}$ & $\begin{array}{l}\text { There are } 4 \text { buttons that lead to kana, } \\
\text { left, up, and down. If the button is } \\
\text { clicked then the player will follow } \\
\text { the direction corresponding button is } \\
\text { clicked }\end{array}$ & succeed \\
\hline $\begin{array}{lr}\text { Button } & \text { Back on } \\
\text { Stage } & \text { Layout } \\
\text { Level } & \\
\end{array}$ & $\begin{array}{l}\text { If Button is clicked it will go to the } \\
\text { Page Layout Stage }\end{array}$ & succeed \\
\hline Button Birthday & $\begin{array}{l}\text { This button will appear if the player } \\
\text { loses } 3 \text { lives. If the button is clicked } \\
\text { will be restarted }\end{array}$ & succeed \\
\hline $\begin{array}{l}\text { Main } \quad \text { Menu } \\
\text { Button }\end{array}$ & $\begin{array}{l}\text { This button will appear if the player } \\
\text { loses } 3 \text { lives. If the button is clicked } \\
\text { going to the Main Page menu }\end{array}$ & succeed \\
\hline Button Up & $\begin{array}{l}\text { Button on the page quiz accretion } \\
\text { and reduction. If the player manages } \\
\text { to answer the quiz correctly it will } \\
\text { display the button further. If the } \\
\text { button is clicked going to the next } \\
\text { level }\end{array}$ & succeed \\
\hline
\end{tabular}

The conclusion of the test chart is that the buttons application button in the application to function properly and in accordance with the expected results.

\section{2) Results Trial}

Testing instructional media educational game is done in primary schools 001, 002, and 003 Samarinda Seberang for 1 st grade students who filled out a questionnaire with the number of 31 boys and girls.
The following are the results of the assessment by male and female students in outline with the following calculation:

$\frac{(p s s \times q s s)+(p s \times q s)+(p k s \times q k s)+(p t s \times q t s)}{q \text { bobot tertinggi } x R} \times \%$

Information:

$\mathrm{R}=$ Number of Respondents $\mathrm{x}$ Number of Questions

$\mathrm{p}$ ss, s, ks, s = Grand Total ss, s, ks, ts

q ss, s, ks, ts = weight of ss, s, ks, ts

TABEL II WEIGHTING

\begin{tabular}{|c|c|}
\hline \multicolumn{2}{|c|}{ Weights (q) } \\
\hline SS & 3 \\
\hline S & 2 \\
\hline KS & 1 \\
\hline TS & 0 \\
\hline
\end{tabular}

TABEL III THE QUESTIONNAIRE

\begin{tabular}{|l|l|l|l|l|l|l|}
\hline No. & \multicolumn{1}{|c|}{ Question } & SS & S & KS & TS & JML \\
\hline 1 & $\begin{array}{l}\text { You are interested to use this } \\
\text { educational game? }\end{array}$ & 12 & 19 & 0 & 0 & 31 \\
\hline 2 & $\begin{array}{l}\text { Do look at this educational } \\
\text { game looks interesting? }\end{array}$ & 13 & 18 & 0 & 0 & 31 \\
\hline 3 & $\begin{array}{l}\text { Is the story in this exciting } \\
\text { educational game? }\end{array}$ & 10 & 17 & 4 & 0 & 31 \\
\hline 4 & $\begin{array}{l}\text { What is the music in this } \\
\text { educational game sound } \\
\text { interesting? }\end{array}$ & 7 & 24 & 0 & 0 & 31 \\
\hline 5 & $\begin{array}{l}\text { Does the question in this } \\
\text { educational game is difficult } \\
\text { to answer? }\end{array}$ & 5 & 26 & 0 & 0 & 31 \\
\hline 6 & $\begin{array}{l}\text { Is the key features on this } \\
\text { educational game to function } \\
\text { properly? }\end{array}$ & 1 & 20 & 10 & 0 & 31 \\
\hline 7 & $\begin{array}{l}\text { Are the instructions for use } \\
\text { of this educational game will } \\
\text { help you in its use? }\end{array}$ & 5 & 26 & 0 & 0 & 31 \\
\hline 8 & $\begin{array}{l}\text { Do see the characters in this } \\
\text { educational game looks } \\
\text { interesting? }\end{array}$ & 9 & 21 & 1 & 0 & 31 \\
\hline TOTAL & 62 & 171 & 15 & 0 & 248 \\
\hline
\end{tabular}

The calculation of the questionnaire as follows:

$=(62 \times 3)+(171 \times 2)+(15 \times 1)+(0 \times 0)$

$3 \times 248$

$=186+342+15+0$

744

$=543$

$744=0.72 \times 100 \%=72$

TABEL IV A SCORE PERCENTAGE

\begin{tabular}{|c|l|}
\hline Score & \multicolumn{1}{c|}{ Information } \\
\hline $10 \%-50 \%$ & $\begin{array}{l}\text { If the value of a score of } 10 \%-50 \%, \text { then the } \\
\text { application category Not Attractive }\end{array}$ \\
\hline $51 \%-75 \%$ & $\begin{array}{l}\text { If the value of a score of 51\%-75\% of the category of } \\
\text { application Quite Interesting }\end{array}$ \\
\hline $76 \%-100 \%$ & $\begin{array}{l}\text { If the value of a score of } 76 \%-100 \%, \text { then the } \\
\text { application category Very Attractive }\end{array}$ \\
\hline
\end{tabular}

Of testing the questionnaire that has been done is to test the calculation of category choice answers from questionnaires that have been distributed in three elementary schools with the number of respondents 31 boys and girls and can be summed Applications Educational Games R. Maze 
obtain a score that is worth $72 \%$ of the category is quite interesting from the start interest respondents use this educational game app, views, stories, music, questions, feature buttons, caption game instructions, and see the character of the game.

\section{CONCLUSIONS AND RECOMMENDATIONS}

Based on the results of research and discussion, the conclusion that can be drawn from this study based on the results of research and discussion, the conclusion that can be drawn from this research is the analysis, plotting, making the design of the interface, making the program by using the software Construct 2 and testing, Based on the results of the questionnaire educational game apps are categorized quite interesting from start to interest respondents use this educational game app, views, stories, music, questions, feature buttons, caption game instructions, and see the character of the game. And the results of testing that has been done in accordance with the expected results.

Researchers realized that the use of educational game apps R. Maze there are still some shortcomings, so there are some suggestions for future development among other things:

1. Need to extend the level to be attractive.

2. Completing the features that are better in the future in order to use applications easier.

3. Results of research has been done is not maximized due to the limited number of android smartphone to demonstrate the application to the primary school male and female students are more numerous until it needs to be made per group and not everyone can play the game application.

4. Applications still has the disadvantage that features less buttons function properly.

[1] Apri Santoso, EN (2013). Design Application of Learning OrganBased Augmented Reality. Palembang: GI STMIK MDP.

[2] Dewi, GP (2012). Game Development Education Introduction Anima Names In English For Elementary Students Learning Media Based on Macromedia Flash. Yogyakarta: Yogyakarta State University.

[3] Dadan Suryana, M. (2014). Early Childhood Itself. Padang: Padang State University.

[4] Febrianza, GG (2016). Chapter 1 What is PhoneGap. Retrieved from github.com:https://github.com/gungunfebrianza/MasteringPhoneGap/blob/master/Chapter1-Apa-itu-PhoneGap.md accessed on 24 July 2019

[5] Hikmatyar, M. (2015). Analysis of Game Development Education "Kwaku" As Indonesian Cultural Heritage Introduction For Children Aged 12-15 years. Yogyakarta: Yogyakarta State University.

[6] Mahmudah, S. (2017). 3D Game Development Education "Finding Treasure" As an Assembly Learning Media Computer For Class X TKJ SMK Negeri 1 Ngawen. Yogyakarta: Yogyakarta State University.

[7] Nawangnugraeni, DA (2015). Educational Games Android In Numbers Introduction Facilities For Early Childhood. Semarang: Semarang State University.

[8] Qalbi, F. (2013). BASIC CONCEPTS OF LOGIC. Retrieved from firman25.blogspot.com: http: ///2013/09/konsep-dasar-logika.html In access on 1-10-2018

[9] redfoc. (2017). Game characters. Retrieved from redfoc.com: https://redfoc.com/rpg-game-tutorial-construct-2/ accessed on 10 December 2018

[10] Rifai, WA (2015). Game Development-Based Environmental Education Android. Yogyakarta: Yogyakarta State universities.

[11] Setyadi, YP (2015). Media Game Development Learning Comprehension Ecrite education in French based Macromedia Flash. Yogyakarta: Yogyakarta State University.
[12] Silalahi, DR (2017). Game "CATCH ME" Using the Construct 2 Game Engine Based on UML diagrams and storyboards. Batam: Batam Polytechnic.

[13] Sumiharsono, MR (2017). Learning Media. East Java: Library Abadi.

[14] Velojet. (2011). Adding SOUND - A BEGINNER'S GUIDE. Retrieved from www.construct.net:

https://www.construct.net/en/tutorials/adding-sound-a-beginnersguide-94 accessed on July 17, 2019 